THE EUROPEAN JOURNAL OF LIFE WRITING VOLUME IX (2020) R25-R30

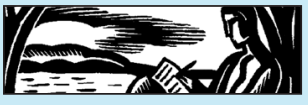

Hanna Meretoja. The Ethics of Storytelling: Narrative Hermeneutics, History, and the Possible (Oxford: Oxford University Press, 2018, ISBN: 9780190649364).

\title{
Sjoerd-Jeroen Moenandar
}

(University of Groningen)

In The Ethics of Storytelling (2018), Hanna Meretoja proposes an approach to the study of narrative that foregrounds how interpretation takes place when people engage in storytelling, either as storyteller or as audience. This, she calls 'narrative hermeneutics': an inquiry into how narratives may instigate interpretation. Reading, listening to, watching a story is seen as an act of meaning-making, almost always leading to many different, sometimes contradictory interpretations. Furthermore, storytelling itself is conceived of as an interpretative act, or, as the author puts it: 'narrative [is] a culturally mediated interpretative practice that makes someone's experiences in a particular situation intelligible by drawing meaningful connections between them' (7). Narrative hermeneutics, in other words, can help us to study the relationship between narrative and experience, since it conceives of the first as a working through of the latter: storytelling is a 'way of making sense of our being in the world' (27).

With this focus on the relationship between narrative and experience, narrative hermeneutics makes it possible to address two issues that remain rather underexplored in the study of life writing. Firstly, the narrative form as a specific way of interpreting experiences. As Meretoja points out, the narrative form itself needs to be studied: 'Narrative presents the narrated experiences as part of a meaningful, connected account', and it does so '[t] hrough emplotment' (49). Narrative, in other words, is not only a recounting of experiences, but also a shaping of our memories. Secondly, narrative as something that teases out interpretations. That is to say, narrative does not only shape (the interpretation of) the experiences that are recounted in a particular story; it also has a regulating effect on (the interpretation of) future experiences of those who come into contact with it. 
In her opening chapters, Meretoja develops a specific form of narrative hermeneutics with which the ethical potential of narratives can be analysed. This potential lies in six aspects that are, according to the author, endemic to narratives and can be presented as a sort of scales with which one can, as it were, 'measure' the ethics of a given narrative. Firstly, the ethical potential of a narrative lies in its capacity to, as the author puts it, 'expand our sense of the possible' (90). A narrative puts up for reflection the ways in which we make sense of and are affected by our lives and the world in which we live them. This may be for better or for worse: while certain narratives explore different possibilities, thereby broadening the horizon of those who engage with these narratives, others limit possible ways of making sense and being affected to those that dominate within the culture in which they are told and received. Secondly, narrative opens up a space for self-reflection, where we can come to an understanding of ourselves and the culture of which we are a part. Such narrative self-reflection can lead to a richer understanding of who we are, beyond identities within our cultures that may confine us to strict stereotypes of e.g. race, gender or class. However, narratives are equally useful to instead perpetuate such stereotypes. Thirdly, as a form of sense-making, narrative may bring about a 'non-subsumptive mode of understanding others': with their focus on singular experiences, narratives can allow us to give meaning to the other 'without confining them to a definition' (111). On the other end of that scale, however, narratives can also limit the other to harmful and stereotypical categories. Fourthly, storytelling can establish a relational space for people to come together and connect, a 'narrative in-between' where experiences can be shared. Ethically sound narrative in-betweens facilitate empowerment and exploration; in ethically problematic ones, 'master narratives' are perpetuated and 'us' and 'them' are separated. Fifthly, narrative offers the possibility of multiple perspectives. There is an ethical danger in this - seductive narratives may present certain perspectives as natural and 'true' by having us identify with subjects at the cost of alternative perspectives. On the other hand, more polyphonic narratives may help us to understand that other people are formed by historical and personal circumstances, and realise that this is also true for ourselves. Sixthly, narrative may function as an ethical inquiry: presenting one specific process of becoming, a narrative can explore how human beings learn how to act in complex moral settings. At worst, the narrative presents its specific example as worthy of either condemnation or praise, foreclosing other ways of being. At best, the narrative activates its audience's moral imagination, teasing out an undogmatic stance, and may thus lead to new ethical insights. 
Developing this narrative hermeneutics, Meretoja draws on a wide range of works from narrative ethics, literary narrative studies and ethical criticism, philosophy of narrative, narrative psychology and cultural memory studies. As such, the first chapters of this book provide a thorough overview of current discussions on the ethics of storytelling and their roots in each of these fields, and Meretoja often takes up thoughtprovoking positions in those discussions. Because of this, these chapters could function as a research guide, especially on the ethics of life writing, offering a series of questions on the interrelatedness of ethics and the narrative form that can be taken up by other scholars. Furthermore, the specific form of narrative hermeneutics that Meretoja develops is a practical and concise method for the analysis of narratives. Thus, a sort of handbook in narrative hermeneutics is offered that could be useful both for researchers and in educational settings.

The introductory chapters that offer these theoretical and methodological reflections are followed by a series of four case studies. Chapter four deals with Julia Franck's Die Mittagsfrau, a fictional family history centred on the traumatic event of a child abandoned by his mother after the war, which Meretoja approaches as the working through of both a personal and a broader cultural past, as a similar event took place in the author's family, but this is also a common phenomenon after military conflicts (149-150). In chapter five, Meretoja compares how Günter Grass's novel Hundejahre and his autobiography Beim Häuten der Zwiebel explore a Nazi past. Chapter six takes on Jonathan Littell's Les Bienveillantes, in which the Holocaust is perceived from a perpetrator's perspective. Chapter seven, finally, analyses David Grossman's To the End of the Land (2008) and Falling Out of Time (2011) as examples of dialogic storytelling.

Thus, somewhat surprising, given her focus on the interrelatedness between experience and narrative, Meretoja mainly discusses fictional narratives, arguing that these can be just as much a narrative working through of memory and experience as more factual forms of narrative. Indeed, her case studies, most notably her chapter on Julia Franck, show that literature often functions as a working through of collective and individual traumas. There is great attention to how this is done in a specifically literary way. Applying her narrative hermeneutics to Les Bienveillantes, for instance, Meretoja shows how the carefully constructed system of a text with its literary mechanisms meets the world of its audience, where readers are not only occupied with the text, but also with the historical contexts of both the text and its readers. In this meeting, she concludes, readers are invited to consider not only the possibilities of the historical world depicted in the novel, but also "what possibilities this might open for us in the current world' (219). Furthermore, in her 
chapter on the life and work of Günter Grass, there is attention for the similarities and differences between the narratives that the author offers in literature and those he offers in his autobiographical writings. In her chapter on Israeli author David Grossman as well, much attention is paid to how a very specific life - the author's - is turned into specific narratives in his literary work, by taking in biographical data and what the author has said about the relevance of these for his own work when analysing his novels and poetry.

Be that as it may, should the starting point not have been instances of life writing, and, indeed, any kind of narrative practices that is meant to directly work through experience, before taking up he particular workings of fictional narrative? Meretoja works the other way around. However, one of the central claims of her book is that narrative functions as a tool to map, to work through, and to shape life experiences. One could argue that establishing how it does so in real-life narratives (not only those already published, but also those that can be gathered through archival or ethnographic field-work) should have come before an inquiry into the special case of fictional narratives.

Meretoja's case studies certainly show how fruitful an inquest into the ethical function of fictional narratives can be, and she presents a convincing argument that the analysis of such narratives offers insight into how narrative can stimulate our moral imagination. However, the literary works that she discusses only reach a very limited audience. Given that Meretoja is interested in how narrative in-betweens are established where storyteller and audience can engage in ethical reflection, such a focus on literature seems limited: forms of storytelling - television shows, webcomics, pop songs - that reach far larger, sometimes even global audiences, could, arguably, have offered more acute case studies and an insight into the ethics of contemporary storytelling, not as an ideal, but as a common practice for millions.

Indeed, the literary works that Meretoja engages with here seem so nuanced that they almost automatically offer the exploration of the selfreflection, non-subsumptive understanding, narrative in-between, multiple perspectives and provocative ethical inquiry that are, according to the author, typical of ethically wholesome narratives. There are examples of ethical failures in some of the narratives presented in these works, but in Meretoja's reading of them, these are imbedded in overarching narratives that are ethical successes and thus function to drive home what ethically sound storytelling should look like. Thus, even though this is not her explicit conclusion, Meretoja seems to lean towards the "utopian tradition' in thinking about art and morality, where (good) literature and art is 'always on the side of the angels' (Carroll 280), even when presenting 
morally compromised personal life stories. An analysis of a narrative that is a complete and unreserved ethical failure would have been instructive.

Criticising an author's choice of corpus is in many ways the easiest form of criticism, and often says more about the critic than the work at hand. Beyond her own case studies, Meretoja's narrative hermeneutics offer a lens that can also be used to analyse life writing, narrative data gathered through fieldwork, popular storytelling, and ethically flawed narratives and I think researchers working on such narratives will find much to work with in The Ethics of Storytelling.

The book also raises two more fundamental questions. Firstly, there is the question whether the six aspects of Meretoja's narrative hermeneutics are really there in the narratives themselves, or should rather be seen as interpretative strategies. I would argue the latter: if we read, listen to or watch any given narrative as open-minded and attentively as Meretoja reads her case studies, it would probably be possible - even if the narrative is a morally dubious one - to turn it into a wonderfully rich in-between, in which our horizon and sense of the possible is broadened.

A second question raised by Meretoja's case studies, is that even though she says at the outset of her book that she does not assume an 'anterior, fixed knowledge of the right means to achieve [the good life]', she does seem to establish certain preconditions for narratives to be considered as wholesome. Thus, she praises the modern novel for presenting "processes of becoming in which moral agents embedded in a particular historical world go through new experiences, make them their own, and are transformed by these experiences as they search for a sense of who they are and what makes life meaningful' (141). But a process of becoming does not always have to be a search for meaning. The expectation that life is meaningful, or has to be made meaningful, could also be restrictive and problematic, and narrative forms that do this could therefore be harmful.

Furthermore, Meretoja often stresses the need for dialogue in order to establish a good narrative: 'dialogic storytelling', as Meretoja calls it, is presented as the best form of storytelling. Such narratives offer 'dialogic encounter-events' where we can meet 'the other' in 'dialogic spaces of possibilities that can have healing and transformative power' (296). But what if the other has no desire to heal or transform us, or be healed or transformed by us? One is reminded of the often heard reply by marginalised spokespeople when asked to inform a majority audience of their experience: 'It is not my responsibility as a marginalized individual to educate you about my experience' (Morgan). If an encounter takes place within the context of deeply ingrained power relations, the expectation of dialogue, healing, and transformation can easily lead to the repetition of histories of exploitation such as colonialism, sexism, racism, classism, 
etc. In other words, dialogue can also be harmful in certain cases, no matter how well the intentions of those involved. One solution could be to replace dialogue with what media scholar Tanja Dreher has called 'ethical listening' (451), where one party in the encounter merely assumes the role of listener, while being attentive to their own privilege and complicity vis à vis the other. Here, transformation and healing may still happen, not through dialogue, but instead by having a monologue run its course without interference, expectations or demands. Forms of storytelling that are radically non-dialogical might be just as wholesome as the dialogical ones that Meretoja seems to favour.

\section{WORKS CITED}

Carroll, Noël. 'Morality and Aesthetics.' In: Michael Kelly (ed.), Encyclopedia of Aesthetics: Volume 3. Oxford: Oxford University Press, 1998, 278-282.

Dreher, Tanja. 'Listening Across Difference. Media and Multiculturalism Beyond the Politics of Voice.' Continuum 23:4 (2009) 445-458. doi: 10.1080/10304310903015712.

Morgan, Elan. '21 Reasons Why It Is Not My Responsibility As a Marginalized Individual to Educate You About My Experience.' Medium, 31 August 2014. https://medium.com/@ schmutzie/why-it-is-not-my-responsibility-as-a-marginalized-individual-to-educate-youabout-my-experience-915b4ec08efd. Date accessed: 20 August 2020. 